\title{
Dietary Total Antioxidant Capacity: A Novel Indicator of Diet Quality in Healthy Young Adults
}

\author{
Blanca Puchau, PhD, M. Ángeles Zulet, PhD, Amaia González de Echávarri, MSc, Helen Hermana M. Hermsdorff, MSc, \\ J. Alfredo Martínez, PhD \\ Department of Nutrition, Food Science, Physiology and Toxicology, University of Navarra, Pamplona, SPAIN
}

Key words: total antioxidant capacity of foods (TACOF), dietary intake, energy density, chronic disease, health

\begin{abstract}
Background: Overall diet quality measurements have been suggested as a useful tool to assess diet-disease relationships. Oxidative stress has been related to the development of obesity and other chronic diseases. Furthermore, antioxidant intake is being considered as protective against cell oxidative damage and related metabolic complications.

Objective: To evaluate potential associations between the dietary total antioxidant capacity of foods (TAC), the energy density of the diet, and other relevant nutritional quality indexes in healthy young adults.

Methods: Several anthropometric variables from 153 healthy participants ( $20.8 \pm 2.7$ years) included in this study were measured. Dietary intake was assessed by a validated food-frequency questionnaire, which was also used to calculate the dietary TAC and for daily energy intake adjustment.

Results: Positive significant associations were found between dietary TAC and Mediterranean energy density hypothesis-oriented dietary scores (Mediterranean Diet Score, Alternate Mediterranean Diet Score, Modified Mediterranean Diet Score), non-Mediterranean hypothesis-oriented dietary scores (Healthy Eating Index, Alternate Healthy Eating Index, Diet Quality Index-International, Diet Quality Index-Revised), and diversity of food intake indicators (Recommended Food Score, Quantitative Index for Dietary Diversity in terms of total energy intake). The Mediterranean Diet Quality Index and Diet Quality Index scores (a Mediterranean and a non-Mediterranean hypothesis-oriented dietary score, respectively), whose lower values refer to a higher diet quality, decreased with higher values of dietary TAC. Energy density was also inversely associated with dietary TAC.

Conclusion: These data suggest that dietary TAC, as a measure of antioxidant intake, may also be a potential marker of diet quality in healthy subjects, providing a novel approach to assess the role of antioxidant intake on health promotion and diet-based therapies.
\end{abstract}

\section{INTRODUCTION}

Overall diet quality measurements have been proposed as useful tools to assess the relationship between diet and disease [1-3]. To determine diet quality, it is necessary to focus on the most important nutritional elements considered in relation to health promotion and disease prevention [4,5]. Nutritional constructs such as dietary patterns [5-8], food variety, or nutritional diversity [4,9] may also be applied. In current methodological approaches characterizing total diet quality, separate nutritional elements or constructs are combined into a single score [1-3]. Furthermore, the term "energy dense" is commonly used to control and characterize foods perceived as unhealthy and to distinguish them from more beneficial nutritional items [10].

On the other hand, the role of oxidative stress in various chronic diseases is receiving increased attention as a result of newly identified links with chronic diseases such as atherosclerosis, obesity, and type 2 diabetes [11]. Indeed, food intake has been related to oxidative stress modulation [12,13], and energy restriction has been described as decreasing the levels

Address correspondence to: J. A. Martínez, Department of Nutrition, Food Science, Physiology and Toxicology, University of Navarra, Calle Irunlarrea 1, 31008 Pamplona, SPAIN. E-mail: jalfmtz@unav.es

Conflict of interest: All authors declare that there are no conflicts of interest concerning the data contained in this manuscript.

Journal of the American College of Nutrition, Vol. 28, No. 6, 648-656 (2009)

Published by the American College of Nutrition 
of oxidative stress mediators [14]. Furthermore, controlling antioxidant intake has been reported to protect against oxidative damage and related inflammatory complications [15]. Thus, a high intake of vitamin C, provitamin A carotenoids, and lycopene is associated with reduced mortality [16]. Given that the concentration of single antioxidants may not reflect the total antioxidant power of food, the concept of total antioxidant capacity (TAC) was introduced [17] as a proxy to describe food quality. Additionally, dietary TAC has been suggested as a novel tool for investigating the potential healthy effects of dietary antioxidants occurring in mixed diets [18] as well as an approach to food characterization.

The objective of this study was to assess the potential relationships and associations between dietary TAC and several validated indicators of overall diet quality in young healthy adults. Indeed, a score able to summarize the dietary total antioxidant capacity is a novel and useful approach, with many potential applications in health promotion and disease prevention or treatment.

\section{MATERIALS AND METHODS}

\section{Subjects}

One hundred fifty-three Caucasian young healthy subjects were recruited to participate in the study (101 women and 52 men; mean age $20.8 \pm 2.7$ years). Clinically healthy subjects were enrolled as previously described [19] when they had no history of disease and did not take any drug on a chronic basis. In accordance with the Declaration of Helsinki [20], after a clear explanation of the study protocol, all subjects gave written informed consent to participate, as previously approved by the Ethics Committee of the University of Navarra (ref: 79/ 2005).

\section{Anthropometric and Body Composition Measurements}

Anthropometric measurements were carried out with the subjects barefoot, wearing only their underwear, and after an overnight fast following standardized protocols [21]. Body weight was measured to the nearest $0.1 \mathrm{~kg}$ by using a Tanita TBF 300 (New York, NY). Body mass index (BMI) was calculated as the body weight divided by the squared height $\left(\mathrm{kg} / \mathrm{m}^{2}\right)$.

\section{Dietary Data}

Habitual diet was assessed with a semiquantitative 136item food-frequency questionnaire (FFQ) previously validated in Spain for energy and nutrient intake [22] and subsequently applied in many further investigations involving nutritional epidemiology studies [23-25]. Each item in the questionnaire included a typical portion size. For each food item, daily food consumption was estimated after multiplying the portion size by the consumption frequency. Nutrient composition of the food items was derived from accepted Spanish food composition tables [26].

\section{Dietary Total Antioxidant Capacity Evaluation}

The dietary TAC score was calculated by adding the individual TAC values from the ferric reducing-antioxidant power assay of each food as previously reported [27-30] and was expressed as TAC in mmol/100 $\mathrm{g}$ of food. To assign a value to TAC-containing foods when not available in previous reports, the data for a similar food item (e.g. same botanical group) were used as a proxy. When the TAC values of cooked food were not published, TAC levels of the fresh food were used to calculate a TAC score. The mean TAC value of the foods contained in each item was used to calculate the dietary TAC score from the FFQ.

\section{Energy Density Calculation}

The dietary energy density value was defined as the ratio between daily energy intake and the daily amount of food consumed $(\mathrm{kcal} / \mathrm{g})$.

\section{Nutritional Index Assessment}

To cover a wider spectrum, several nutritional indexes were calculated regarding Mediterranean Diet, non-Mediterranean hypothesis-oriented dietary patterns, and diversity of food intake. Moreover, their association with antioxidant intake was assessed. Thus, the Mediterranean Diet Quality Index (MDQI) [31], the Mediterranean Diet Score (MDS) [8], the Alternate Mediterranean Diet Score (AMDS) [5], and the Modified Mediterranean Diet Score (MMDS) [7] were calculated. Likewise, considering non-Mediterranean hypothesis-oriented dietary patterns, the Healthy Eating Index (HEI) [1], the Alternate Healthy Eating Index (AHEI) [4], the Diet Quality Index (DQI) [3], the Diet Quality Index-International (DQII) [32], and the Diet Quality Index-Revised (DQIR) [33] were also computed. Regarding dietary variety, the Recommended Food Score (RFS) [4] and the Quantitative Index for Dietary Diversity in kcal (QIDD) [9] were assessed. Detailed information to estimate these scores can be found in Table 1 and in the aforementioned references.

\section{Statistical Analysis}

To assess the relationships between the dietary TAC intake and the analyzed nutritional indexes, tests for linear trends across quintiles of dietary TAC were performed. Partial 
Table 1. Calculation of the Dietary Indexes

\begin{tabular}{|c|c|c|}
\hline Index & Reference & Index Calculation \\
\hline Healthy Eating Index (HEI) & Kennedy et al. 1995 [1] & $\begin{array}{l}\text { Ten components scored 0-10 points each based on the food guide } \\
\text { pyramid and the Dietary Guidelines for Americans (1990): grains } \\
\text { (bread, cereal, rice, pasta), vegetables, fruits, dairy products } \\
\text { (includes yogurt and cheese), meat group (includes meat, poultry, } \\
\text { fish, dry beans, eggs, nuts), total fat, saturated fat, cholesterol, } \\
\text { sodium, variety. }\end{array}$ \\
\hline $\begin{array}{l}\text { Alternate Healthy Eating Index } \\
\text { (AHEI) }\end{array}$ & McCullough et al. 2006 [53] & $\begin{array}{l}\text { Eight components scored } 0-10 \text { points each based on dietary } \\
\text { recommendations: vegetables, fruit, nuts and soy, ratio of white to } \\
\text { red meat, cereal fiber, trans fat, PUFA:SFA, alcohol. Multivitamin } \\
\text { use scored } 0-7.5 \text { according to the length of use. }\end{array}$ \\
\hline Diet Quality Index (DQI) & Patterson et al. 1994 [3] & $\begin{array}{l}\text { Eight components scored } 10-0 \text { points each based on dietary } \\
\text { recommendations: total fat, saturated fat, cholesterol, vegetables and } \\
\text { fruits, cereals and legumes, proteins, sodium, calcium. }\end{array}$ \\
\hline $\begin{array}{l}\text { Diet Quality Index-International } \\
\text { (DQII) }\end{array}$ & Kim et al. 2003 [32] & $\begin{array}{l}\text { Seventeen components in } 4 \text { groups: } \\
\text { - Variety: overall food group variety, within-group variety for protein } \\
\text { source. } \\
\text { - Adequacy: vegetables, fruits, cereals, fiber, protein, iron, calcium, } \\
\text { vitamin C. } \\
\text { - Moderation: total fat, saturated fat, cholesterol, sodium, empty-calorie } \\
\text { foods. } \\
\text { - Overall balance: macronutrient ratio (carbohydrate:protein:fat), fatty } \\
\text { acid ratio (PUFA:MUFA:SFA). }\end{array}$ \\
\hline $\begin{array}{l}\text { Diet Quality Index-Revised } \\
\text { (DQIR) }\end{array}$ & Haines et al. 1999 [33] & $\begin{array}{l}\text { Thirteen components in } 3 \text { groups: } \\
\text { - Variety: overall food group variety. } \\
\text { - Adequacy: total fat, saturated fat, cholesterol, fruits, vegetables, } \\
\text { cereals, calcium, iron. } \\
\text { - Moderation: total added sugar, discretionary fat, sodium, alcohol. }\end{array}$ \\
\hline $\begin{array}{l}\text { Mediterranean Diet Quality } \\
\text { Index (MDQI) }\end{array}$ & Scali et al. 2001 [31] & $\begin{array}{l}\text { Seven items scoring } 2-0 \text { points each: saturated fat, cholesterol, meat, } \\
\text { olive oil, vegetables and fruits, fish, cereals. }\end{array}$ \\
\hline $\begin{array}{l}\text { Mediterranean Diet Score } \\
\quad(\text { MDS })\end{array}$ & Tur et al. 2004 [8] & $\begin{array}{l}\left.\text { Adherence (percentage } \mathrm{i}_{\mathrm{i}}\right)=\left[\left(\Sigma \mathrm{z}_{\mathrm{i}}-\Sigma \mathrm{z}_{\min }\right) \times 100\right] /\left(\Sigma \mathrm{z}_{\max }-\Sigma \mathrm{z}_{\min }\right) \text {, } \\
\text { where } \mathrm{z}_{\mathrm{i}} \text { was obtained by adding up all the } \mathrm{z} \text { scores for the favorable } \\
\text { Mediterranean dietary component (legumes, cereals and potatoes, } \\
\text { fruits, vegetables, fish, alcohol, MUFA:SFA) and subtracting the } \mathrm{z} \\
\text { values for meat and meat products and dairy products (all foods and } \\
\text { nutrients were previously adjusted for total energy intake). }\end{array}$ \\
\hline $\begin{array}{l}\text { Alternate Mediterranean Diet Score } \\
\text { (AMDS) }\end{array}$ & Trichopoulou et al. 2005 [5] & $\begin{array}{l}\text { Eight items scoring } 0-1 \text { point according to their frequency of } \\
\text { consumption: vegetables }(+) \text {, legumes }(+) \text {, fruits and nuts }(+) \text {, cereals } \\
(+) \text {, dairy products }(-) \text {, meat and meat products }(-) \text {, MUFA:SFA } \\
(+) \text {, moderate alcohol consumption }(+) \text {. }\end{array}$ \\
\hline $\begin{array}{l}\text { Modified Mediterranean Diet Score } \\
\text { (MMDS) }\end{array}$ & Trichopoulou et al. 2005 [7] & $\begin{array}{l}\text { Nine items scoring } 0-1 \text { point each according to their frequency of } \\
\text { consumption: vegetables }(+) \text {, legumes }(+) \text {, fruits and nuts }(+) \text {, cereals } \\
(+) \text {, dairy products }(-) \text {, meat and meat products }(-) \text {, fish }(+) \text {, } \\
\text { MUFA:SFA }(+) \text {, moderate alcohol consumption }(+) \text {. }\end{array}$ \\
\hline Recommended Food Score (RFS) & $\begin{array}{l}\text { Kant et al. } 2000 \text { [54], } \\
\text { McCullough et al. } 2002 \text { [4] }\end{array}$ & $\begin{array}{l}\text { One point (for each) if food items in the following categories were } \\
\text { consumed at least once a week: Vegetables ( } 26 \text { varieties), fruits (18 } \\
\text { varieties), protein foods ( } 6 \text { varieties), cereals ( } 5 \text { varieties), dairy } \\
\text { products ( } 1 \text { variety). }\end{array}$ \\
\hline $\begin{array}{l}\text { Quantitative Index for Dietary } \\
\text { Diversity in terms of total energy } \\
\text { intake (QIDD-k) }\end{array}$ & Katanoda et al. 2006 [9] & $\begin{array}{l}\text { QIDD-k }=\left(1-\Sigma_{\mathrm{j}}^{\mathrm{n}} \operatorname{prop}(\mathrm{j})^{2}\right) /(1-1 / \mathrm{n}) \text {, where } \operatorname{prop}(j) \text { is the proportion } \\
\text { of food group }(\mathrm{s}) j \text { that contributes to total energy intake, } n \text { is the } \\
\text { number of food groups, and } j=1,2, \ldots, n \text {. The food groups measured } \\
\text { as percentage of total energy intake considered were: cereals, nuts } \\
\text { and seeds, potatoes, sugars and confectioneries, legumes, vegetables, } \\
\text { fruits, fish and shellfish, meats, eggs, milk and other dairy products, } \\
\text { oils and fats, seasonings and spices, alcoholic beverages and other } \\
\text { beverages, and processed foods and others. }\end{array}$ \\
\hline
\end{tabular}

MUFA $=$ monounsaturated fatty acids, PUFA $=$ polyunsaturated fatty acids, SFA $=$ saturated fatty acids 
Table 2. Data (Mean \pm SD) for Young Adults Categorized by Quintiles of Dietary TAC Value

\begin{tabular}{|c|c|c|c|c|c|c|}
\hline & \multicolumn{5}{|c|}{ Quintiles of Dietary TAC $(\mathrm{mmol} / \mathrm{d})$} & \multirow[b]{3}{*}{$p$ for Trend } \\
\hline & Q1 & Q2 & Q3 & Q4 & Q5 & \\
\hline & $\begin{array}{c}2.05-4.72 \\
(\mathrm{n}=30)\end{array}$ & $\begin{array}{c}4.75-6.29 \\
(\mathrm{n}=31)\end{array}$ & $\begin{array}{c}6.31-7.59 \\
(\mathrm{n}=31)\end{array}$ & $\begin{array}{l}7.77-9.84 \\
(\mathrm{n}=31)\end{array}$ & $\begin{array}{c}10.09-22.25 \\
(\mathrm{n}=30)\end{array}$ & \\
\hline Age $(y)$ & $21.0 \pm 2.9$ & $20.5 \pm 2.4$ & $21.2 \pm 3.0$ & $21.2 \pm 3.2$ & $20.4 \pm 1.8$ & 0.421 \\
\hline $\operatorname{Sex}(\mathrm{M} / \mathrm{F})$ & $13 / 17$ & $16 / 15$ & $8 / 23$ & $9 / 22$ & $6 / 24$ & 0.011 \\
\hline BMI $\left(\mathrm{kg} / \mathrm{m}^{2}\right)$ & $22.7 \pm 2.5$ & $22.8 \pm 2.9$ & $22.0 \pm 2.3$ & $21.8 \pm 2.3$ & $21.5 \pm 2.8$ & 0.049 \\
\hline \multicolumn{7}{|l|}{ Energy intake } \\
\hline $\begin{array}{r}(\mathrm{kcal} / \mathrm{d}) \\
\text { HEI score }\end{array}$ & $\begin{array}{c}1955 \pm 483 \\
55.3 \pm 9.7\end{array}$ & $\begin{array}{c}2761 \pm 742 \\
59.7 \pm 9.0\end{array}$ & $\begin{array}{c}2599 \pm 832 \\
63.2 \pm 9.3\end{array}$ & $\begin{aligned} 2545 & \pm 647 \\
64.0 & \pm 12.1\end{aligned}$ & $\begin{array}{c}3439 \pm 1084 \\
67.7 \pm 9.7\end{array}$ & $\begin{array}{l}<0.001 \\
<0.001\end{array}$ \\
\hline AHEI score & $36.8 \pm 3.4$ & $40.7 \pm 4.0$ & $43.4 \pm 5.2$ & $46.4 \pm 5.9$ & $53.1 \pm 5.9$ & $<0.001$ \\
\hline DQI score & $10.7 \pm 1.8$ & $9.9 \pm 1.9$ & $9.7 \pm 1.6$ & $9.5 \pm 2.2$ & $9.2 \pm 1.8$ & $<0.001$ \\
\hline DQII score & $57.7 \pm 5.2$ & $63.1 \pm 3.6$ & $62.7 \pm 5.0$ & $62.8 \pm 4.7$ & $64.4 \pm 5.2$ & $<0.001$ \\
\hline DQIR score & $49.9 \pm 9.9$ & $59.7 \pm 8.2$ & $59.6 \pm 8.8$ & $61.4 \pm 11.5$ & $66.4 \pm 7.7$ & $<0.001$ \\
\hline MDQI score & $8.6 \pm 1.9$ & $7.9 \pm 1.5$ & $7.5 \pm 1.5$ & $6.7 \pm 1.9$ & $6.3 \pm 1.3$ & $<0.001$ \\
\hline MDS score & $35.8 \pm 10.5$ & $40.7 \pm 9.7$ & $40.7 \pm 13.8$ & $49.2 \pm 12.3$ & $56.6 \pm 14.0$ & $<0.001$ \\
\hline AMDS score & $1.9 \pm 0.9$ & $2.8 \pm 1.2$ & $3.0 \pm 1.5$ & $3.6 \pm 1.3$ & $4.8 \pm 0.9$ & $<0.001$ \\
\hline MMDS score & $2.1 \pm 1.1$ & $3.0 \pm 1.3$ & $3.4 \pm 1.7$ & $4.0 \pm 1.5$ & $5.3 \pm 1.1$ & $<0.001$ \\
\hline RFS score & $12.8 \pm 4.2$ & $17.4 \pm 4.5$ & $19.0 \pm 5.6$ & $20.7 \pm 4.2$ & $25.0 \pm 6.4$ & $<0.001$ \\
\hline QIDD-k score & $0.92 \pm 0.02$ & $0.91 \pm 0.04$ & $0.92 \pm 0.06$ & $0.93 \pm 0.02$ & $0.94 \pm 0.02$ & 0.029 \\
\hline $\begin{array}{l}\text { Energy density } \\
\quad(\mathrm{kcal} / \mathrm{g})\end{array}$ & $1.36 \pm 0.27$ & $1.42 \pm 0.34$ & $1.37 \pm 0.38$ & $1.20 \pm 0.27$ & $1.19 \pm 0.30$ & 0.002 \\
\hline
\end{tabular}

AHEI = Alternate Healthy Eating Index, AMDS = Alternate Mediterranean Diet Score, BMI = body mass index, DQI $=$ Diet Quality Index, DQII $=$ Diet Quality IndexInternational, DQIR = Diet Quality Index-Revised, HEI $=$ Healthy Eating Index, MDQI $=$ Mediterranean Diet Quality Index, MDS $=$ Mediterranean Diet Score, MMDS = Modified Mediterranean Diet Score, QIDD = Quantitative Index for Dietary Diversity, RFS $=$ Recommended Food Score, TAC $=$ total antioxidant capacity.

correlations adjusted for sex, BMI, and daily energy intake were performed to further explain relationships between dietary TAC and nutritional indexes and to evaluate the association between dietary TAC and several food groups. Results are presented as means \pm standard deviations. Statistical analysis were performed with SPSS version 15.0 (SPSS Inc., Chicago, IL) for Windows XP (Microsoft, Redmond, WA). All $p$ values were 2-tailed. Only $p$ values below 0.05 were considered statistically significant.

\section{RESULTS}

The sample distributed by quintiles of dietary TAC is reported in Table 2. Although age did not vary, the sex distribution changed through the dietary TAC quintiles. Moreover, BMI decreased with higher quintiles of dietary TAC. Regarding dietary quality, Mediterranean hypothesisoriented dietary scores (MDS, AMDS, MMDS), non-Mediterranean hypothesis-oriented dietary scores (HEI, AHEI, DQII, DQIR), and diversity of food intake (RFS, QIDD-k) presented higher values through the quintiles of dietary TAC. The MDQI and DQI scores (a Mediterranean and a nonMediterranean hypothesis-oriented dietary score, respectively), whose lower scores refer to a higher diet quality, decreased with higher values of dietary TAC. Energy density appeared to decrease with higher levels of dietary TAC. Furthermore, the partial correlations between dietary TAC and diet quality measured by the previously mentioned indexes after adjusting for sex, BMI, and daily energy intake are shown (Table 3). For all the analyzed scores, the association was statistically significant. As occurred in the quintiles analysis, the trend was positive for all indexes (higher values of dietary TAC were associated with higher scores for the diet quality indexes), apart from MDQI and DQI scores or energy density, whose values were lower when the diet quality increased. Additionally, partial correlations were carried out between dietary TAC values and food group consumption (Table 4); these showed positive and significant associations for vegetables, fruits, fish, nuts, and alcoholic beverages, after adjusting for sex, BMI, and daily energy intake. A similar trend was observed for low-fat dairy products, whereas cereals, baked goods (such as doughnuts or muffins), and fast food (such as hamburgers or pizzas) showed negative and significant associations after adjusting for sex, BMI, and daily energy intake.

As a means of separately evaluating the association between dietary TAC and energy density, Fig. 1 shows the contributions of each food group to energy density, which is higher in vegetable oils, animal fats, nuts, and sugars, and also to dietary TAC, which is higher in vegetables, sodas, fruits, alcoholic beverages, and nuts. 
Table 3. Partial Correlation Analysis between Dietary TAC Values (mmol/d) and Diet Quality-Related Indexes after Adjusting for Sex, BMI, and Daily Energy Intake

\begin{tabular}{lcrc}
\hline & \multirow{2}{*}{$\begin{array}{c}\text { Expected Healthy } \\
\text { Trend }\end{array}$} & \multicolumn{2}{c}{ Partial Correlations $(\mathrm{n}=153)$} \\
\cline { 3 - 4 } & $(+)$ & 0.44 & $<$ \\
\hline HEI score & $(+)$ & 0.61 & $<0.001$ \\
AHEI score & $(-)$ & -0.32 & $<0.001$ \\
DQI score & $(+)$ & 0.32 & $<0.001$ \\
DQII score & $(+)$ & 0.43 & $<0.001$ \\
DQIR score & $(-)$ & -0.36 & $<0.001$ \\
MDQI score & $(+)$ & 0.48 & $<0.001$ \\
MDS score & $(+)$ & 0.46 & $<0.001$ \\
AMDS score & $(+)$ & 0.47 & $<0.001$ \\
MMDS score & $(+)$ & 0.53 & $<0.001$ \\
RFS score & $(+)$ & 0.29 & $<0.001$ \\
QIDD-k score & $(-)$ & -0.57 & $<0.001$ \\
ED values & &
\end{tabular}

AHEI $=$ Alternate Healthy Eating Index, AMDS $=$ Alternate Mediterranean Diet Score, $\mathrm{ED}=$ energy density, $\mathrm{DQI}=$ Diet Quality Index, DQI $=$ Diet Quality Index-International, DQIR $=$ Diet Quality Index-Revised, HEI $=$ Healthy Eating Index, MDQI = Mediterranean Diet Quality Index, MDS = Mediterranean Diet Score, MMDS = Modified Mediterranean Diet Score, QIDD $=$ Quantitative Index for Dietary Diversity, RFS $=$ Recommended Food Score, $\mathrm{TAC}=$ total antioxidant capacity, $\mathrm{BMI}=$ body mass index.

\section{DISCUSSION}

Oxidative stress and inflammation-related indicators have been associated with the onset and development of chronic disease [11,34]. Thus, nail and dietary selenium have been involved in oxidative stress-related diseases in healthy adults $[19,35,36]$, which highlights the putative relationships between disease development and antioxidant intake. In this context, many studies report the ability of the dietary intake to modulate antioxidant status after the acute consumption of antioxidantrich foods [37-40]. However, the lack of effect of an increased antioxidant intake on the balance between antioxidant status and oxidative stress reported in a recent study [41] could indicate a homeostatic mechanism, in which endogenous antioxidants compensate the influx of dietary antioxidants [17].

To assess dietary antioxidant intake, researchers have described recently that an FFQ is able to determine the dietary TAC intake in different samples of subjects in a reliable manner $[42,43]$. Thus, we performed similar calculations using an FFQ that had been previously validated for estimating food and nutrient intake [22-25], including settings related to inflammation and oxidative stress issues [19,35,36,44,45]. Moreover, according to our results, the TAC intake was related to such food groups as vegetables, fruits, and legumes [43], which are among the most important contributors of dietary antioxidant nutrients or components [16] and dietary TAC values [27]. Furthermore, a recent study has suggested that dietary TAC is positively associated with plasma total
Table 4. Partial Correlations between Dietary TAC Values $(\mathrm{mmol} / \mathrm{d})$ and Antioxidant Nutrients and Food Groups Intake of the Subjects after Adjusting for Sex, BMI, and Daily Energy Intake

\begin{tabular}{lrc}
\hline & \multicolumn{2}{c}{ Partial Correlations $(\mathrm{n}=153)$} \\
\cline { 2 - 3 } & $\mathrm{r}$ & $p$ value \\
\hline Food groups & & \\
Vegetables $(\mathrm{g} / \mathrm{d})$ & 0.52 & $<0.001$ \\
Fruits $(\mathrm{g} / \mathrm{d})$ & 0.60 & $<0.001$ \\
Cereals $(\mathrm{g} / \mathrm{d})$ & -0.17 & 0.038 \\
Low-fat dairy products $(\mathrm{g} / \mathrm{d})$ & 0.14 & 0.086 \\
Fish $(\mathrm{g} / \mathrm{d})$ & 0.31 & $<0.001$ \\
Nuts $(\mathrm{g} / \mathrm{d})$ & 0.19 & 0.018 \\
Alcoholic beverages $(\mathrm{g} / \mathrm{d})$ & 0.22 & 0.009 \\
Baked goods $(\mathrm{g} / \mathrm{d})$ & -0.23 & 0.005 \\
Fast food $(\mathrm{g} / \mathrm{d})$ & -0.24 & 0.003 \\
\hline
\end{tabular}

$\mathrm{TAC}=$ total antioxidant capacity, $\mathrm{BMI}=$ body mass index.

antioxidant capacity [44], suggesting that dietary TAC may constitute a useful tool in antioxidant intake assessment.

Dietary indexes are designed to estimate the diet quality by means of a single score that results from computing different components such as foods, food groups, or a combination of foods and nutrients. These scores are hypothesis-oriented food patterns and reflect known or suspected diet and disease associations [46]. All assessed food patterns share some characteristics with each other and with dietary TAC [43], such as encouraging the consumption of high amounts of fruits and vegetables, two food groups with a recognized high content of antioxidant compounds [27]. However, nutritional indexes try to gather some diverse aspects of the diet value, which could be separated into 2 main groups: those that try to merge existing evidence and recommendations about promoting healthy and avoiding deleterious foods and nutrients (HEI, AHEI, DQI, DQII, DQIR, RFS, QIDD) and those that seek to capture the healthy aspects of the Mediterranean diet (MDQI, MDS, AMDS, MMDS). Thus, DQIR has been associated with circulating $\beta$-carotene, among other plasma antioxidants, in men [2]. In this sense, dietary TAC has been related to prediction of circulating levels of $\beta$-carotene [47]. The association between dietary TAC and Mediterranean hypothesis-oriented dietary scores could thus be explained by the assumed features of the Mediterranean dietary pattern, which combines abundant plant foods (fruits, vegetables, cereals, nuts, seeds, wine, and olive oil) with a large potential amount of active dietary antioxidants [48]. This statement is consistent with our results, where dietary TAC was higher in those food groups involving vegetables, fruits, nuts, and alcoholic beverages (considering wine and beer). The fact that dairy products (but not low-fat dairy products), baked goods, and fast food were negatively associated with dietary TAC could be because those foods with a higher antioxidant compound 
A

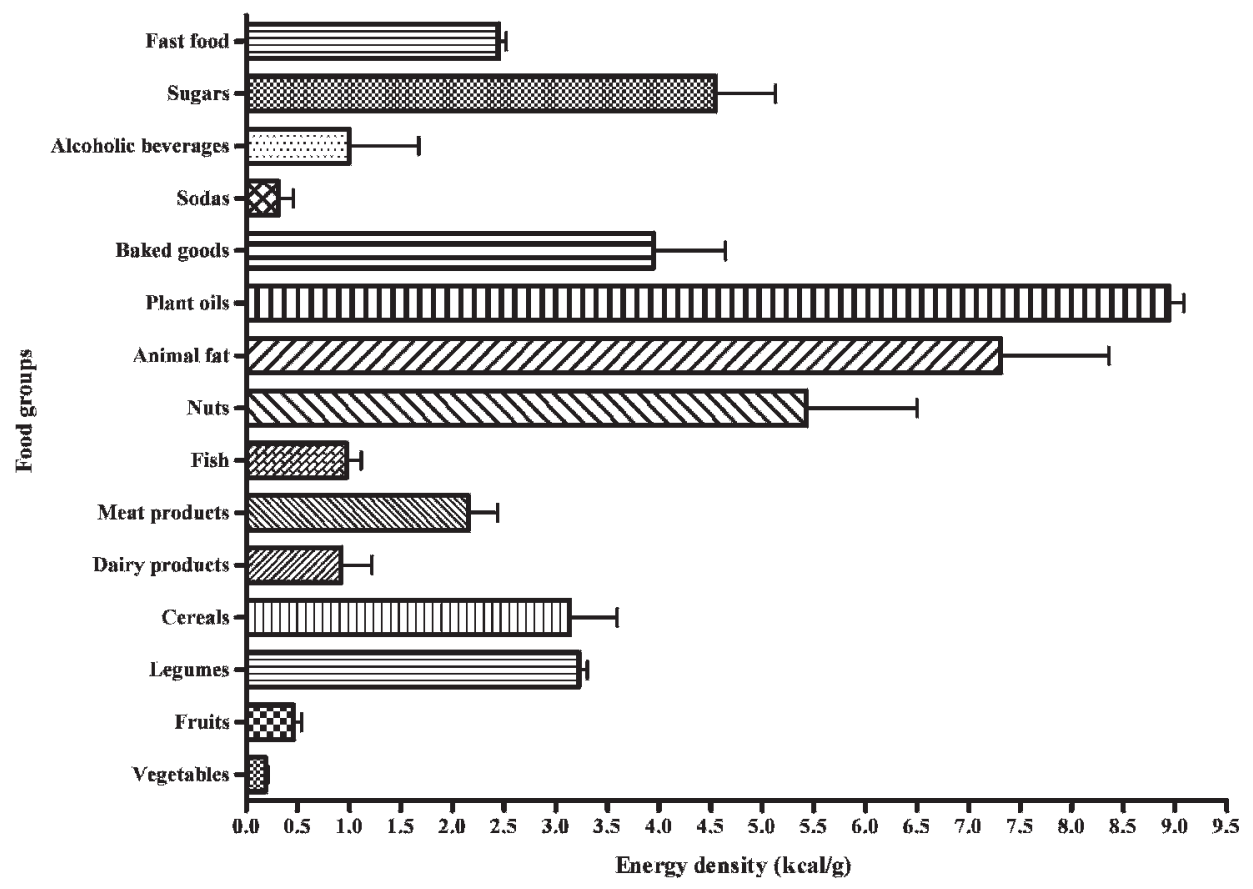

B

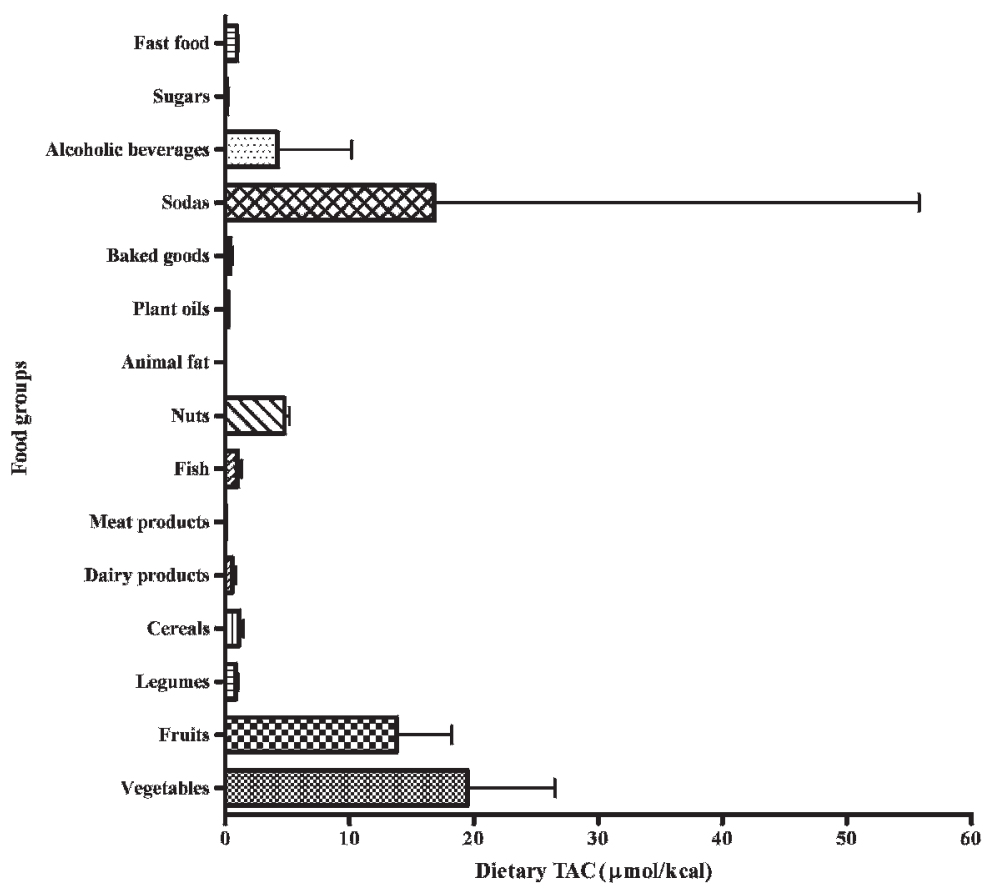

Fig. 1. Energy density (A) and dietary TAC (B) values of various food groups. Values shown are means and standard deviations ( $\mathrm{n}=153)$.

content are also lower in fat content. Surprisingly, cereals were negatively correlated with dietary TAC. The lack of a positive association may be because this group refers not only to whole cereals but also to refined cereal products as well as some sugar-rich baked goods.
Furthermore, energy density has been defined as the amount of energy in a given weight of food [49], so energydense foods provide higher calorie content on a weight basis than nutrient-rich foods such as vegetables and fruits [10]. Moreover, diet quality has been associated with higher nutrient 
intake and self-rated health in women [50]. In this sense, our results support previous findings [51] suggesting that energydense/nutrient-poor foods were consumed at the expense of nutrient-dense foods, resulting in increased risk of high energy intake, marginal micronutrient intake, poor compliance with nutrient- and food group-related dietary guidance, and low serum concentrations of vitamins and carotenoids.

The present study has some limitations that must be mentioned. It has been published that FFQs are not adequate for the assessment of the intake of fruits and vegetables (which are among the major contributors to dietary TAC) over long periods of time because of the seasonality of fruits and vegetables [52]. Moreover, FFQs have a limited number of food items, increasing the error in dietary TAC calculation because of the large differences in TAC values among foods included in the same item. Indeed, the fact that very statistically significant associations with reliable indexes have been found supports the validity of this dietary approach.

In conclusion, these data suggest that dietary TAC, as a measure of antioxidant intake, may also be a potential marker of diet quality in healthy subjects, which may have implications for research into the onset and development of chronic diseases. Thus, the applications of this novel approach to computing dietary total antioxidant capacity of foods will be useful to assess the role of antioxidant intake as a single factor in a field of increasing scientific interest such as antioxidant consumption and disease prevention or therapy.

\section{ACKNOWLEDGMENTS}

We thank Blanca Martínez de Morentin and Salomé Pérez for assistance with the data collection and all those who volunteered to participate in the study. This work has been supported by the Health Department of the Government of Navarra (22/2007), the Línea Especial about Nutrition, Obesity and Health (LE/97), Ibercaja, the ADA fellowships scheme of the University of Navarra, and the Capes Foundation of the Ministry of Education of Brazil (375605-0). Also, the assistance of the Director of the Foreign Language Institute at the University of Navarra in a final reading of the last version of the manuscript is gratefully acknowledged.

\section{REFERENCES}

1. Kennedy ET, Ohls J, Carlson S, Fleming K: The Healthy Eating Index: design and applications. J Am Diet Assoc 95:1103-1108, 1995.

2. Newby PK, Hu FB, Rimm EB, Smith-Warner SA, Feskanich D, Sampson L, Willett WC: Reproducibility and validity of the Diet Quality Index Revised as assessed by use of a food-frequency questionnaire. Am J Clin Nutr 78:941-949, 2003.
3. Patterson RE, Haines PS, Popkin BM: Diet quality index: capturing a multidimensional behavior. J Am Diet Assoc 94:5764, 1994.

4. McCullough ML, Feskanich D, Stampfer MJ, Giovannucci EL, Rimm EB, Hu FB, Spiegelman D, Hunter DJ, Colditz GA, Willett WC: Diet quality and major chronic disease risk in men and women: moving toward improved dietary guidance. Am J Clin Nutr 76:1261-1271, 2002.

5. Trichopoulou A, Bamia C, Trichopoulos D: Mediterranean diet and survival among patients with coronary heart disease in Greece. Arch Intern Med 165:929-935, 2005.

6. Sanchez-Villegas A, Martinez JA, De Irala J, Martinez-Gonzalez MA: Determinants of the adherence to an "a priori" defined Mediterranean dietary pattern. Eur J Nutr 41:249-257, 2002.

7. Trichopoulou A, Orfanos P, Norat T, Bueno-de-Mesquita B, Ocke MC, Peeters PH, van der Schouw YT, Boeing H, Hoffmann K, Boffetta P, Nagel G, Masala G, Krogh V, Panico S, Tumino R, Vineis P, Bamia C, Naska A, Benetou V, Ferrari P, Slimani N, Pera G, Martinez-Garcia C, Navarro C, Rodriguez-Barranco M, Dorronsoro M, Spencer EA, Key TJ, Bingham S, Khaw KT, Kesse E, Clavel-Chapelon F, Boutron-Ruault MC, Berglund G, Wirfalt E, Hallmans G, Johansson I, Tjonneland A, Olsen A, Overvad K, Hundborg HH, Riboli E, Trichopoulos D: Modified Mediterranean diet and survival: EPIC-elderly prospective cohort study. Br Med J 330:991, 2005.

8. Tur JA, Romaguera D, Pons A: Adherence to the Mediterranean dietary pattern among the population of the Balearic Islands. Br J Nutr 92:341-346, 2004.

9. Katanoda K, Kim HS, Matsumura Y: New Quantitative Index for Dietary Diversity (QUANTIDD) and its annual changes in the Japanese. Nutrition 22:283-287, 2006.

10. Drewnowski A: Concept of a nutritious food: toward a nutrient density score. Am J Clin Nutr 82:721-732, 2005.

11. Fulop T, Tessier D, Carpentier A: The metabolic syndrome. Pathol Biol (Paris) 54:375-386, 2006.

12. Mohanty P, Ghanim H, Hamouda W, Aljada A, Garg R, Dandona $P$ : Both lipid and protein intakes stimulate increased generation of reactive oxygen species by polymorphonuclear leukocytes and mononuclear cells. Am J Clin Nutr 75:767-772, 2002.

13. Mohanty P, Hamouda W, Garg R, Aljada A, Ghanim H, Dandona P: Glucose challenge stimulates reactive oxygen species (ROS) generation by leucocytes. J Clin Endocrinol Metab 85:2970-2973, 2000.

14. Dandona P, Mohanty P, Ghanim H, Aljada A, Browne R, Hamouda W, Prabhala A, Afzal A, Garg R: The suppressive effect of dietary restriction and weight loss in the obese on the generation of reactive oxygen species by leukocytes, lipid peroxidation, and protein carbonylation. J Clin Endocrinol Metab 86:355-362, 2001

15. Dandona P, Aljada A, Bandyopadhyay A: Inflammation: the link between insulin resistance, obesity and diabetes. Trends Immunol 25:4-7, 2004.

16. Agudo A, Cabrera L, Amiano P, Ardanaz E, Barricarte A, Berenguer T, Chirlaque MD, Dorronsoro M, Jakszyn P, Larranaga N, Martinez C, Navarro C, Quiros JR, Sanchez MJ, Tormo MJ, Gonzalez CA: Fruit and vegetable intakes, dietary antioxidant nutrients, and total mortality in Spanish adults: findings from the Spanish cohort of the European Prospective Investigation into Cancer and Nutrition (EPIC-Spain). Am J Clin Nutr 85:1634-1642, 2007. 
17. Serafini M, Del Rio D: Understanding the association between dietary antioxidants, redox status and disease: is the Total Antioxidant Capacity the right tool? Redox Rep 9:145-152, 2004.

18. Brighenti F, Valtuena S, Pellegrini N, Ardigo D, Del Rio D, Salvatore S, Piatti P, Serafini M, Zavaroni I: Total antioxidant capacity of the diet is inversely and independently related to plasma concentration of high-sensitivity C-reactive protein in adult Italian subjects. Br J Nutr 93:619-625, 2005.

19. Puchau B, Zulet MA, Gonzalez de Echavarri A, Navarro-Blasco I, Martinez JA: Selenium intake reduces serum C3, an early marker of metabolic syndrome manifestations, in healthy young adults. Eur J Clin Nutr 63:858-864, 2009.

20. Benatar SR: Linking moral progress to medical progress: new opportunities for the Declaration of Helsinki. World Med J 50:1113, 2004.

21. Gibson RS: "Principles of Nutritional Assessment." New York: Oxford University Press, 2005.

22. Martin-Moreno JM, Boyle $\mathrm{P}$, Gorgojo L, Maisonneuve $\mathrm{P}$, Fernandez-Rodriguez JC, Salvini S, Willett WC: Development and validation of a food frequency questionnaire in Spain. Int $\mathrm{J}$ Epidemiol 22:512-519, 1993.

23. Alcacera MA, Marques-Lopes I, Fajo-Pascual M, Foncillas JP, Carmona-Torre F, Martinez-Gonzalez MA: Alcoholic beverage preference and dietary pattern in Spanish university graduates: the SUN cohort study. Eur J Clin Nutr 62:1178-1186, 2008.

24. Bes-Rastrollo M, Sabate J, Gomez-Gracia E, Alonso A, Martinez JA, Martinez-Gonzalez MA: Nut consumption and weight gain in a Mediterranean cohort: the SUN study. Obesity 15:107-116, 2007.

25. Bes-Rastrollo M, Sanchez-Villegas A, de la Fuente C, de Irala J, Martinez JA, Martinez-Gonzalez MA: Olive oil consumption and weight change: the SUN prospective cohort study. Lipids 41:249256, 2006.

26. Moreiras O, Carvajal A, Cabrera L: "Tablas de Composición de Alimentos [Food Composition Tables]." Madrid: Pirámide, 2005.

27. Halvorsen BL, Carlsen MH, Phillips KM, Bohn SK, Holte K, Jacobs DR Jr, Blomhoff R: Content of redox-active compounds (ie, antioxidants) in foods consumed in the United States. Am J Clin Nutr 84:95-135, 2006.

28. Halvorsen BL, Holte K, Myhrstad MC, Barikmo I, Hvattum E, Remberg SF, Wold AB, Haffner K, Baugerod H, Andersen LF, Moskaug O, Jacobs Jr DR, Blomhoff R: A systematic screening of total antioxidants in dietary plants. J Nutr 132:461-471, 2002.

29. Pellegrini N, Serafini M, Colombi B, Del Rio D, Salvatore S, Bianchi M, Brighenti F: Total antioxidant capacity of plant foods, beverages and oils consumed in Italy assessed by three different in vitro assays. J Nutr 133:2812-2819, 2003.

30. Pellegrini N, Serafini M, Salvatore S, Del Rio D, Bianchi M, Brighenti F: Total antioxidant capacity of spices, dried fruits, nuts, pulses, cereals and sweets consumed in Italy assessed by three different in vitro assays. Mol Nutr Food Res 50:1030-1038, 2006.

31. Scali J, Richard A, Gerber M: Diet profiles in a population sample from Mediterranean southern France. Public Health Nutr 4:173182, 2001.

32. Kim S, Haines PS, Siega-Riz AM, Popkin BM: The Diet Quality Index-International (DQI-I) provides an effective tool for crossnational comparison of diet quality as illustrated by China and the United States. J Nutr 133:3476-3484, 2003.
33. Haines PS, Siega-Riz AM, Popkin BM: The Diet Quality Index revised: a measurement instrument for populations. J Am Diet Assoc 99:697-704, 1999.

34. Péres-Matute P, Zulet MA, Martinez JA: Reactive species and diabetes: counteracting oxidative stress to improve health. Curr Opin Pharmacol 9:771-779, 2009.

35. Puchau B, Zulet MA, Urtiaga G, Navarro-Blasco I, Martinez JA: Asymmetric dimethylarginine association with antioxidants intake in healthy young adults: a role as an indicator of metabolic syndrome features. Metabolism 58:1483-1488, 2009.

36. Zulet MA, Puchau B, Hermsdorff HH, Navarro C, Martinez JA: Dietary selenium intake is negatively associated with serum sialic acid and metabolic syndrome features in healthy young adults. Nutr Res 29:41-48, 2009.

37. Hassimotto NM, Pinto MD, Lajolo FM: Antioxidant status in humans after consumption of blackberry (Rubus fruticosus L.) juices with and without defatted milk. J Agric Food Chem 56:11727-11733, 2008.

38. Maxwell S, Cruickshank A, Thorpe G: Red wine and antioxidant activity in serum. Lancet 344:193-194, 1994.

39. Modun D, Music I, Vukovic J, Brizic I, Katalinic V, Obad A, Palada I, Dujic Z, Boban M: The increase in human plasma antioxidant capacity after red wine consumption is due to both plasma urate and wine polyphenols. Atherosclerosis 197:250-256, 2008.

40. Pitsavos C, Panagiotakos DB, Tzima N, Chrysohoou C, Economou M, Zampelas A, Stefanadis C: Adherence to the Mediterranean diet is associated with total antioxidant capacity in healthy adults: the ATTICA study. Am J Clin Nutr 82:694-699, 2005.

41. Valtuena S, Pellegrini N, Franzini L, Bianchi MA, Ardigo D, Del Rio D, Piatti P, Scazzina F, Zavaroni I, Brighenti F: Food selection based on total antioxidant capacity can modify antioxidant intake, systemic inflammation, and liver function without altering markers of oxidative stress. Am J Clin Nutr 87:1290-1297, 2008.

42. Pellegrini N, Salvatore S, Valtuena S, Bedogni G, Porrini M, Pala V, Del Rio D, Sieri S, Miglio C, Krogh V, Zavaroni I, Brighenti F: Development and validation of a food frequency questionnaire for the assessment of dietary total antioxidant capacity. J Nutr 137:9398, 2007.

43. Rautiainen S, Serafini M, Morgenstern R, Prior RL, Wolk A: The validity and reproducibility of food-frequency questionnaire-based total antioxidant capacity estimates in Swedish women. Am J Clin Nutr 87:1247-1253, 2008.

44. Puchau B, Zulet MA, González de Echávarri A, Hermsdorff HH, Martinez JA: Dietary total antioxidant capacity is negatively associated with some metabolic syndrome features in healthy young adults. Nutrition, in press.

45. Zulet MA, Puchau B, Hermsdorff HH, Navarro C, Martinez JA: Vitamin A intake is inversely related with adiposity in healthy young adults. J Nutr Sci Vitaminol (Tokyo) 54:347-352, 2008.

46. Willett WC, McCullough ML: Dietary pattern analysis for the evaluation of dietary guidelines. Asia Pac J Clin Nutr 17(suppl 1):S75-S78, 2008.

47. Valtuena S, Del Rio D, Pellegrini N, Ardigo D, Franzini L, Salvatore S, Piatti PM, Riso P, Zavaroni I, Brighenti F: The total antioxidant capacity of the diet is an independent predictor of plasma beta-carotene. Eur J Clin Nutr 61:69-76, 2007.

48. Visioli F, Galli C: The role of antioxidants in the Mediterranean diet. Lipids 36(suppl):S49-S52, 2001. 
49. Bes-Rastrollo M, van Dam RM, Martinez-Gonzalez MA, Li TY, Sampson LL, Hu FB: Prospective study of dietary energy density and weight gain in women. Am J Clin Nutr 88:769-777, 2008.

50. Collins CE, Young AF, Hodge A: Diet quality is associated with higher nutrient intake and self-rated health in mid-aged women. J Am Coll Nutr 27:146-157, 2008.

51. Kant AK: Consumption of energy-dense, nutrient-poor foods by adult Americans: nutritional and health implications. The third National Health and Nutrition Examination Survey, 1988-1994. Am J Clin Nutr 72:929-936, 2000.

52. Marks GC, Hughes MC, van der Pols JC: Relative validity of food intake estimates using a food frequency questionnaire is associated with sex, age, and other personal characteristics. J Nutr 136:459465, 2006.

53. McCullough ML, Willett WC: Evaluating adherence to recommended diets in adults: the Alternate Healthy Eating Index. Public Health Nutr 9:152-157, 2006.

54. Kant AK, Schatzkin A, Graubard BI, Schairer C: A prospective study of diet quality and mortality in women. JAMA 283:21092115,2000 .

Received January 26, 2009; revision accepted November 10, 2009. 